\title{
Primer registro de Cyclospora cayetanensis en Aguascalientes (México) Confirmación de dos casos
}

Gómez-Torres JR*,Montañez -Díaz ME*, Delgado-Guerrero G**

\section{- Resumen}

- En un lapso de dos años se presentaron dos casos - clínicos humanos con trastornos digestivos semejantes. - Para su estudio y ante la sospecha de una parasitosis - se realizó un examen coproparasitoscópico, tinción de - Kinyoun y fluorescencia húmeda directa en los que - se demostró, la presencia de estructuras, que por sus - propiedades morfométricas y tintoreales corresponde - a Cyclospora cayetanensis. El primero de los casos es - un paciente de sexo masculino de 27 años de edad - con trastornos digestivos y diarrea después de una estancia breve en la ciudad de México e ingerir alimentos en la calle. El segundo caso es una mujer de 37 años cuyo antecedente fue consumir, exclusivamente, una ensalada en un restaurante de la ciudad de Aguascalientes y días después presentar molestias digestivas semejantes al caso anterior. En ambos casos los frotis teñidos con Kinyoun (BAAR modificado) y expuestos a la luz ultravioleta presentaron ooquistes con diferentes grados de tinción y con una intensa fluorescencia (distintiva de ellos). LUXMÉDICA 2010;5(I4):11-15

Palabras clave: Cyclospora cayetanensis, cyclosporiasis

\section{Primer caso}

Paciente de sexo masculino de 27 años de edad originario de Aguascalientes refiere que cinco días después de regresar de la ciudad de México presentó cuadros periódicos de diarrea, malestar abdominal con dolor y cansancio, permaneciendo en estas condiciones 25 días más. Durante su estancia en la ciudad de México ingirió bebidas y alimentos callejeros. A los 30 días de su retorno solicitó consulta y se le sugirió se realizara una serie de estudios coproparasitoscópicos para determinar la posible causa de su malestar. En la primera muestra y por observación directa se demostró la presencia de estructuras esféricas con aspecto de mora que por sus dimensiones (10-12 $\mu \mathrm{m}$ ) y forma podían corresponder a ooquistes

* Profesor investigador del departamento de Microbiología, Centro de Ciencias Biomédicas, UAA.

** Alumno del décimo semestre de Medicina del Centro de Ciencias Biomédicas, UAA. 
de Cryptosporidum o Cyclospora. La muestra fue sometida a tinción de Kinyoun para poder hacer la diferenciación, confirmándose por sus propiedades corresponden a $C$. cayetanensis. El paciente recibió tratamiento con trimetoprim con sulfametoxazol (dosis de 160/800 mg cuatro veces al día durante 10 días) con curso satisfactorio hasta la fecha.

\section{Segundo caso}

Paciente de sexo femenino de 37 años de edad, insiste y refiere que raramente ingiere comida en la calle, pero que 15 días antes de enfermar lo hizo en restaurante del lugar (Aguascalientes) consumiendo una ensalada. Ocho días después inicia su padecimiento al presentar sensación de malestar abdominal; con distensión, meteorismo aumentado y cefalea. Dos días después presenta diarrea con evacuaciones inconsistentes, grisáceas y sin dolor abdominal. Se automedica e ingiere comida astringente, pero continúa con periodos de diarrea intermitente durante los siguientes 15 días. Solicita consulta médica administrándose antibióticos. Ante la falta de respuesta al tratamiento se hace examen corproparasitoscópico, en el cual se demuestra la presencia de abundantes levaduras. Se suspende el tratamiento con antibióticos pero continua con evacuaciones semilíquidas. Cinco días después se hace coproparasitoscopía nuevamente y se observan estructuras esféricas, con aspecto de mórula de aproximadamente $10 \mu \mathrm{m}$ (figura 1) y gran cantidad de grasa (esteatorrea) confirmando posteriormente, al realizar la tinción de Kinyoun, la presencia de Cyclospora (figura 2). Se realiza observación húmeda directa de las laminillas para buscar autofluorescencia la cual fue positiva en estas estructuras (figura 3). Las preparaciones teñidas con Kinyoun también fueron sometidas a fluorescencia observando que los ooquistes teñidos con el colorante dan una intensa fluorescencia roja (figura 4), mientras que las menos teñidas disminuye la fluorescencia proporcionalmente. El paciente recibió tratamiento con trimetoprim con sulfametoxazol, pero a los 7 días de tratamiento persistían las evacuaciones diarreicas. En ese momento se hizo frotis y tinción con Kinyoun, identificándose ooquistes. Nos llamó la atención que los ooquistes durante el tratamiento no fijan el colorante. La paciente continuó con el tratamiento y actualmente está asintomática.

\section{Introducción}

Cyclospora cayetanensis inicialmente denominada Cyanobacterium-like body ${ }^{1}$, es un protozoo parásito cuyo nombre se debe a investigadores del departamento de parasitología de la universidad Cayetano Heredia de Lima Perú; en Baltimore, USA. Ortega y colaboradores lo caracterizaron como coccidio por su tipo de multiplicación sexual y asexual ${ }^{2}$. El primer caso humano de infección por Cyclospora fue informado en $1979^{2}$. A mediados de la década de 
1980 y sobretodo después de 1994 ha sido registrada más frecuentemente. ${ }^{3-9} C$. cayetanensis es un coccidio que se asocia en individuos inmunodeprimidos a cuadros de enteritis prolongada y a veces grave, en pacientes inmunocompetentes con antecedentes de ser visitantes extranjeros o residentes de países en desarroIlo. ${ }^{10-12}$ Puede afectar a individuos de cualquier edad, informándose también la presencia de portadores asintomáticos. ${ }^{3,13}$ La infección en individuos inmunocompetentes después de un periodo tiende a autolimitarse.

Este parásito se transmite por la ingestión de agua o alimentos contaminados con evacuaciones que contienen ooquistes maduros de Cyclospora. ${ }^{13,14}$ En el proceso de transmisión los ooquistes requieren días a semanas para su maduración en el medio externo para ser infectantes, por lo anterior la infección de persona a persona es poco probable. Existen reportes de brotes de infección por Cyclospora en Chicago y Nepal. ${ }^{15,16}$ Recientemente, el Control Disease Center (CDC) informó un extenso brote de infección por este coccidio en USA y Canadá13 ${ }^{3}$, causado probablemente por el consumo de frutas frescas, entre ellas frambuesas.

Las estructuras de los ooquistes de $C$. cayetanensis en heces fecales, presentan forma esférica, refráctiles, de 8 a $10 \mu \mathrm{m}$ de diámetro, cuyo interior presenta una masa con aspecto de mórula (figura 1). Son refractarios a las tinciones corrientes, pero con tinción de Ziehl-Neelsen modificado (Kinyoun), algunos ooquistes se tiñen intensamente y otros lo hacen de forma leve o no se tiñen, estos últimos se ven como quistes hialinos (vidrio molido) (figura 2). Observando en las preparaciones húmedas directas los ooquistes presentan autofluorescencia y las preparaciones teñidas con Kinyoun bajo la luz ultravioleta presentan fluorescencia intensa de color rojo. ${ }^{3,17}$

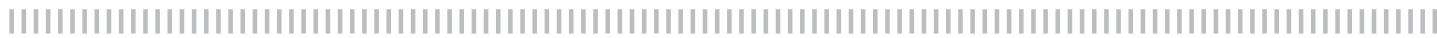

\section{Material y métodos}

Las muestras obtenidas de heces de los paciente fueron sometidas a examen parasitológico seriado con tres muestras procesadas según el método de Burrows. ${ }^{17} \mathrm{La}$ observación de la muestra en fresco con solución salina isotónica y el objetivo $90 \mathrm{X}$ nos sugirió la sospecha de ooquistes de Cyclospora (figura 1). Por lo anterior se sometió a luz ultravioleta para demostrar su propiedad de autofluorescencia (figura 3). Se prepararon frotis fecales que se tiñeron con técnica de Kinyoun y se observaron con objetivo $100 \times$ (figura 2 )

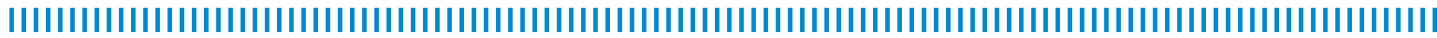

\section{Resultados y discusión}

La primera característica que llamó la atención en ambos pacientes fue la coincidencia de la sintomatología, haciendo énfasis en periodos de diarrea, antecedentes alimentarios y el aspecto de ambas muestras fecales de color grisáceo amarillento, descrito antes por otros autores. ${ }^{18,21}$ 
La observación directa en fresco, de ooquistes con su morfología característica de vidrio molido y sus medidas, nos indujo a sospechar la presencia de Cyclospora. Al realizar la tinción de Kinyoun observamos abundantes ooquistes teñidos de forma variable. Unos se tiñeron de color rojo intenso, otros de color rosa y algunos no se tiñeron (figura 2). Los ooquistes observados en fresco se sometieron a luz ultravioleta $480 \lambda$ de longitud de onda y presentaron autofluorescencia (figura 3). Estos se midieron y mostraron una variación de 8 a $10 \mu \mathrm{m}$ de diámetro. Su morfología, tamaño, características irregulares tintoreales con Kinyoun (algunos autores señalan que muestran una "Y" (figura 5) y la autofluo-

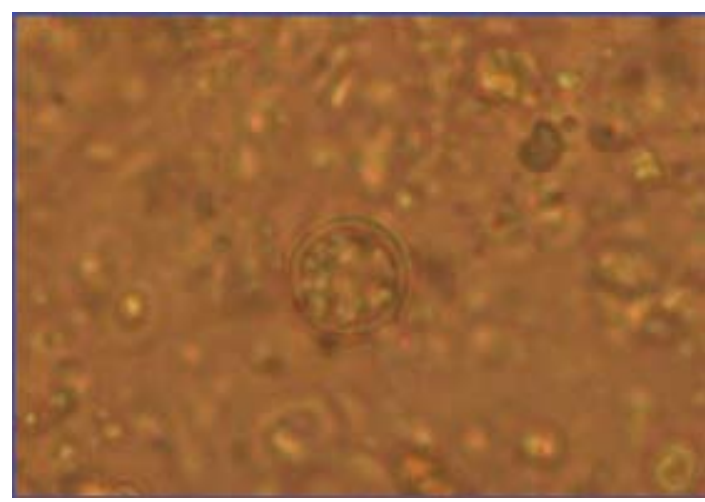

Figura 1. Observación directa húmeda de ooquistes de $C$. cayetanensis mostrando la apariencia de vidrio molido (90X).

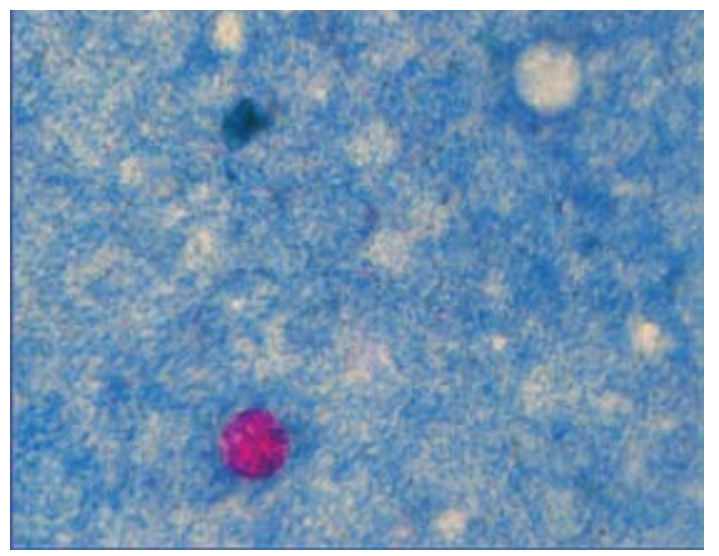

Figura 2. Ooquiste de C. cayetanensis teñido con técnica de Kinyoun 40 X.)(Obsérvese la diferencia en la coloración) rescencia nos confirmó el diagnóstico para diferenciarlo de Cryptosporidium parvum, coccidio semejante pero de menor tamaño (de 4-6 $\mu \mathrm{m}$ ), que se tiñe irregularmente en forma individual y no en forma irregular de grupo como $C$. cayetanensis.

La identificación de Cyclospora con técnicas, que, aunque son sencillas de realizar no se hacen de rutina en la mayoría de los laboratorios clínicos y menos aún con equipo de fluorescencia. Un hecho relevante, observado por nosotros fue que al exponerlos con microscopia de fluorescencia los quistes más teñidos con Kinyoun, son los que presentaron fluorescencia más intensa (figura 4).

Al segundo paciente se le repitieron los exámenes seriados coproparasitoscópicos y frotis teñidos un mes después del tratamiento, ya asintomático y con heces bien formadas, que nos mostró la presencia de ooquistes que no se tiñeron al practicarle la tinción con Kinyoun, fenómeno que nos desconcertó y que no debemos pasar por alto. Creemos que la diarrea presentada por los pacientes en forma periódica alterna, señalada en la literatura pudiese corresponder al ciclo biológico de los coccidios con la liberación de merozoitos a nivel intestinal ${ }^{2}$. En México existen pocos reportes ${ }^{9}$ y en nuestro estado no encontramos ninguno.

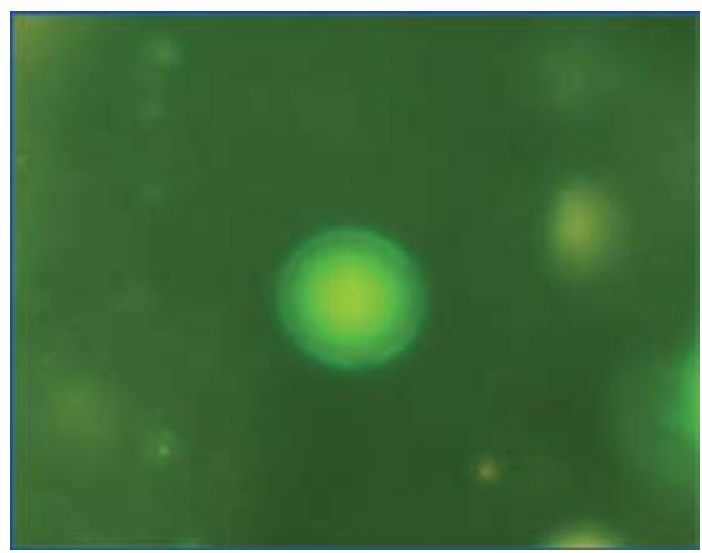

Figura 3. Ooquiste preparación húmeda directa mostrando autofluorescencia. (90X) 


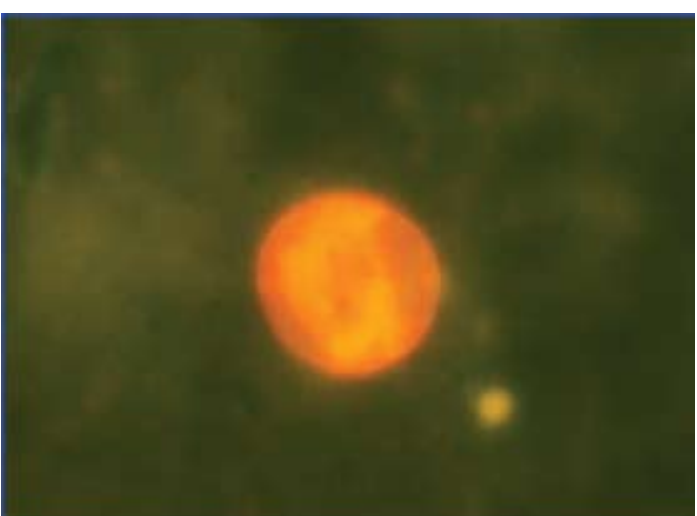

Figura 4. Frotis teñido con técnica de Kinyoun y observado con luz UV (90X) (ooquiste).

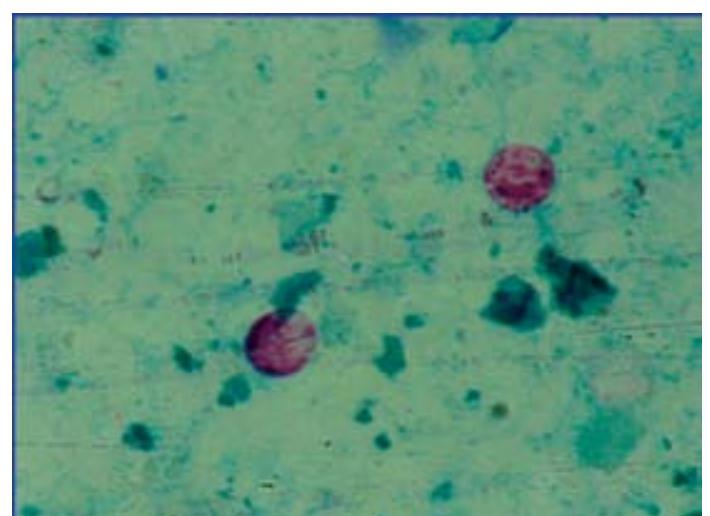

Fig 5. Oquistes teñidos con Kinyoun 40X (Algunos presentan una " $Y$ " más teñida, flecha)

\section{Bibliografía}

1 Bendall R P. Lucas S. Moody A et. al. Diarrohea associated with Cyanobacterium like-bodies; a new coccidian anteritis of man. Lancet 1993; 341: 590592.

2 Ortega Y R. Sterling C H. Gilman R H et.al. Cyclospora species. A new protozoan pathogen of humans. New Engl J Med 1993; 328: 1308-1313.

3 Pollok E C G. Bendall R P. Moody A et.tal. Travellers diarrohea associated with Cyanobacterium Like-bodies Lancet 1992; 340: 556-557.

4 Ashford R W. Warshurst D C.Reid G D F. Human infection with Cyanobacterium-like bodies. Lancet 1993; 341: 1034.

5 Soave R. Dubey J P. Ramos L J. Tummings M. A new intestinal pathogen? (Abstract) Clin Res 1986; 34: 553.

6 Melvin-Brooke. Métodos de laboratorio para diagnostico de parasitosis intestinales 1995; 79-82.

7 Botero-Garces j, Montoya-Palacio MN, Barguil Jl, Castaño-Gonzalez A. An Outbreak of Cyclospora cayetanenesis In Medellin Colombia. Rev

8 Torres-Slimming PA, Mundaca CC, Moran M Quispe J, Colina O, Bacon DJ, Lescano Ag, Gilman, RH Bazes DL. Outbreak of cyclosporiasis at a naval base in Lima Peru. Am J Trop Med Hyg. 2006 Sep;75(3): 546-8

9 Ayala-Gaytán JJ, Díaz-Olachea C, Riojas-Montalvo P, Palacios-Martínez C. Cyclosporidiosis: clinical end diagnostic characteristics of an epidemic outbreak. Rev Gastroenterol Mex.2004; 69(4): 226-9

10 Hart A S. Ridingre M T. Soundarajan R H. et.al. Novel organism associated with chronic diarrohea in AIDS. Lancet 1990; 335: 169-170.
11 Long E G. Ebrahimzadehm A. Withe E H. et.al. Alga associated with diarrohea in patients with acquired immunodeficiency sindrome an in travels. J Clin Microbiol 1990; 28: 101-104.

12 Cifuentes O J. Porras C G. Bendall R P. et.al. Cyclospora cayetanenesis in patient with and withaut AIDS. Billiary disease and other clinical manifestation. Clin Inf Dis 1995; 21: 1092- 1097.

13 From the center for disease control and preventions. Outbreaks of Cyclospora cayetanensis. Infections United States. J Am Med Ass. 1996; 183-276.

14 Connors AB. Shlim R D. Foodborne transmissión of Cyclospora. Lancet 1995; 346: 1634.

15 Hoce W CH. Echeverria P. Raha R et.al. Prevalence of Cyclospora species end other enteric pathogens among children less than 5 years of age in Nepal. J Clin Microbiol 33: 3058-3060.

16 Center for Disease Control. Outbreakof diarrohea illness associated Whit Cyanobacteria (blue-green algae)- like bodies Chicago and Nepal.1989 and 1990. WWR 1991; 40 325-327.

17 Burrows R. A new fixative a technics for diagnostico of intestinal parasites. Am J Clin Pathol. 1967; 48: 342.

18 Casemore D P. Cyclospora: another new pathogen. J Med Microbiol 1994; 41: 217-219.

19 Wurtz R. Cyclospora: a newly identified intestinal pathogen of humans. Clin Inf Dis 1994; 18: 620623.

20 Berlin O G W. Novak S M. Porchen R K. et.al. Recovery of Cyclospora organismo from patients with prolonged diarrohea. Clin Inf 1994; 18: 606-609.

21 Wool. ZimmermanS K. Needham C A. Cyclospora species as a gastrointestinal pathogen in inmmunocompetent host. J Clin Microbiol 1995 33: 1267-1269. 